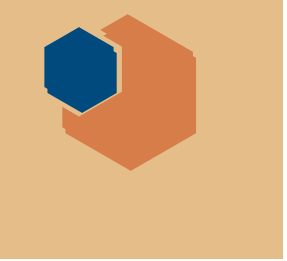

\title{
NATO's science program funds materials research
}

\author{
www.nato.int/science Twitter @NATO_SPS
}

W hen materials scientists seek research funding, NATO does not immediately come to mind. Yet NATO has an annual budget of $€ 12.5$ million for civil science through its Science for Peace and Security Program. Through this program, it has funded several materials-focused projects that fall under the auspices of its strategic goals and key priorities.

"We fund by application rather than by technology," said Michael Switkes, the science advisor for the program. "If there are materials science issues that have terrorism, energy security, or environmental security applications, and are defense and security related, then they can get funded. We want people to see that NATO is not only a military organization, we also provide support for technology development."
NATO's science program dates back to 1958, coinciding with the Soviet Unions' launch of Sputnik, the first artificial satellite. The original goal of the program was to bring together European and US research communities to strengthen the trans-Atlantic link. The science program's focus shifted with the end of the Cold War. The program's main purpose today is to foster innovation and to provide a platform for forging partnerships between countries.

The program funds international research projects, Advanced Study Institutes (summer schools) for young scientists, and advanced research workshops. Research projects are typically funded for two to three years with a budget of $€ 250,000-400,000$. NATO currently has 28 members and 41 partner countries with which the organization has formal agreements.

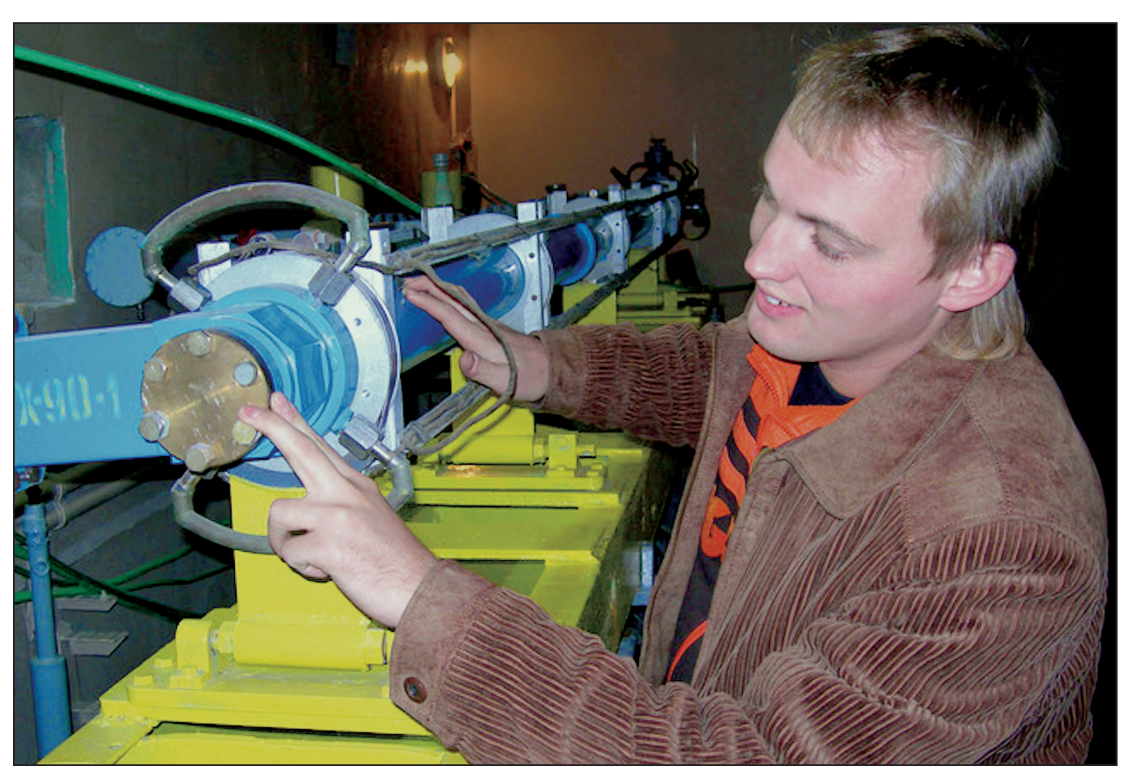

Scientists at the National Science Center in Kharkiv, Ukraine, are building a cost-effective $\mathrm{x}$-ray generator that produces high-energy $\mathrm{x}$-rays needed for high-resolution image detection systems in the field of medicine, illicit trafficking, explosion detection, forensic detection, and environmental security. Ukraine is the top beneficiary of the NATO Science for Peace and Security Program.
To be considered for funding, research projects need to be international collaborations, with at least one researcher from a NATO member country and at least one from a partner country. "Science and technology is a much easier way to engage with partner countries with whom it may be more difficult to have frank conversations about delicate subjects like defense," Switkes said. "It's a really good way to build relationships with these countries until they're ready to have a closer partnership with NATO."

Materials are a prominent theme in many NATO-funded science projects. A majority of the counterterrorism projects have focused on advanced sensor technologies to detect hazardous chemicals such as explosives and radioactive materials. Of the 74 new activities to receive funding in 2014, one project by researchers from France, Portugal, Tunisia, and Egypt aims to use photocatalytic nanotechnology for light, durable and easy-to-use self-decontaminating textiles, which decompose harmful chemicals used as warfare agents in order to protect the wearer. Anotherwith scientists from Germany, France, Ukraine, and Israel-seeks to develop new nanocarbon-polymer composite materials for protective shields that absorb microwave radiation. The technology could protect vital equipment from electromagnetic interference when applied as a coating or paint.

Other projects include novel fuelcell materials for portable, durable power; metal nanocrystals for highly sensitive detection of biochemical agents; ionic compounds to prevent marine vessel corrosion and biofouling; nanomaterials for security applications; nanostructured metal-semiconductor thin films for solar-energy harvesting; and novel terahertz radiation sources for explosives detection. 
The program also supports fundamental early-stage research "if there's a plausible link to defense and security," Switkes said. For example, one currently funded project involves spintronics materials, which hold promise for encryption and computing.

A critical issue of focus for NATO at present is detection technologies, he says. That includes detecting concealed explosives and weapons from a distance in real time without disrupting the flow of traffic, such as in mass transit. This will require novel materials detection methods as well as damage-reducing materials such as blast-mitigating walls and foams.

Grant proposals are first peer-reviewed by an independent scientific evaluation group of about 30 experts from NATO countries. The recommended projects are then sent to a 28-member committee of NATO allies in Brussels who have the final say. "Mostly we look for two things," Switkes said. "One is scientific and technical excellence. The other is impact, whether it's on something nearterm or on future work in that area."
Political implications and budgets also have bearing on the final approval decision. "We've had in the past a very scientific project that brought together scientists from all three South Caucasus countries, Georgia, Armenia, and Azerbaijan," he said. "We love to have such projects, which bring together several of our partner countries regionally."

Deadlines for grant applications are usually in the spring, summer, and fall. The next deadline is May 15, 2016. Prachi Patel
Science groups urge global accord on "Open Data in a Big Data World" www.icsu.org/science-international

$F_{0}$ our major international science organizations are calling for global endorsement of an accord to help ensure open access to volumes of "big data," that increasingly are the basis of research and policymaking. Leaders of these organizations met on the sidelines of Science Forum South Africa in December to discuss the accord and the plans to seek endorsements in a 12-month global campaign.

The accord-developed by the International Council for Science (ICSU), the InterAcademy Partnership, the International Social Science Council (ISSC), and The World Academy of Sciences (TWAS) for the advancement of science in developing countriesincludes a set of guiding principles on open access to big data necessary to protect the scientific process and ensure that developing countries can participate more fully in the global research enterprise. Limits on access to big data knowledge, they warn, raises the risk that progress will slow down in areas such as advanced health research, environmental protection, food production, and the development of smart cities.

Geoffrey Boulton, President of CODATA, ICSU's Committee on Data, and leader of the working group that developed the accord, said, "As the data revolution accelerates and the scientific potential of big data becomes clearer, it is timely that the major representative bodies of international science promote the importance of open data as a means of maximizing creativity, maintaining rigor and ensuring that knowledge is a global public good, rather than just a private good."

The digital revolution has created an unprecedented explosion in the data available for analysis by scientists, policymakers, and others. Extremely large data sets, or big data, help researchers to recognize subtle but powerful patterns in areas ranging across the sciences, from security to genetic research and human behavior. Such data will be crucial for analyzing and achieving the United Nation's new Sustainable Development Goals, according to the Department of Science and Technology in South Africa. The "privatization of knowledge," however, could constrain this research.

The accord identifies the opportunities and challenges of the data revolution as an overarching interest for global science policy. It proposes 12 principles to guide the practice and practitioners of open data, focusing on the roles played by scientists, publishers, libraries, and other stakeholders, and on technical requirements for open data. It also assesses the "boundaries of openness."
According to the accord, "Open data should be the default position for publicly funded science. Exceptions should be limited to issues of privacy, safety, security and commercial use in the public interest. Proposed exceptions should be justified on a case-by-case basis and not as blanket exclusions."

"Open access to data will be essential if developing countries are to join in the benefits of the big data revolution," said Romain Murenzi, Executive Director of TWAS. "If developing nations are left behind, if they are unable to make a full contribution to the global research enterprise, that will be costly, not only for them and their people, but for all nations."

Organizers and working group members from about 10 countries in Africa, Asia, Europe, Latin America, and North America participated in the meetings to shape the accord. Over the next 12 months, the campaign will collect endorsements for the accord from other science, education, and policy bodies, with final results anticipated in the third quarter of 2016.

ICSU President Gordon McBean of Canada said, "Data is the fabric of modern science. The challenge for science today is to keep pace with the digital revolution, and for that we need a strong international framework setting out the principles for an open data regime that enables all nations and societies to benefit equally from the opportunities it presents." 